\title{
SEMIOLOGIA OTORRINOLARINGOLÓGICA
}

\author{
OTORHINOLARYNGOLOGIC SEMIOLOGY
}

Wilma Terezinha Anselmo Lima, José Antonio Aparecido de Oliveira

Docentes do Departamento de Oftalmologia e Otorrinolaringologia da Faculdade de Medicina de Ribeirão Preto da Universidade de São Paulo.

CORRESPONDÊNCIA: Departamento de Oftalmologia e Otorrinolaringologia da Faculdade de Medicina de Ribeirão Preto - Campus Universitário - CEP: 14.048-900 - Ribeirão Preto - SP - FAX: (016) 633-5839

ANSELMO-LIMA WT \& OLIVEIRA JAA de Semiologia otorrinolaringológica. Medicina, Ribeirão Preto, 29: 61-66, jan./mar. 1996.

RESUMO: Nesta revisão dirigida ao graduando em Medicina e ao médico não especialista, apresentou-se os principais elementos semiológicos das fossas nasais, seios paranasais, laringe, faringe e ouvidos.

UNITERMOS: Otorrinolaringologia. Diagnóstico Otorrinolaringológico.

A propedêutica otorrinolaringológica deve ser realizada por partes: a das fossas nasais e seios paranasais, a da faringe, a da laringe e a dos ouvidos. A seguir, descreveremos cada uma delas.

\section{1 - FOSSAS NASAIS E SEIOS PARANASAIS}

Os exames mais simples e, comumente, utilizados para a inspeção das fossas nasais são as rinoscopias anterior e posterior, auxiliados pelo sistema de iluminação indireta, o espelho frontal ou iluminação direta, o fotóforo.

\section{1 - Rinoscopia anterior}

Inicialmente é feita uma inspeção simples da pirâmide nasal, narinas e vestíbulo, cuja finalidade é a procura de desvios da linha média, sinais inflamatórios externos, luxações do subsepto, deformidades da porção do septo nasal. A palpação, em seguida, pode detectar pontos dolorosos. Com o espéculo nasal, o examinador afasta a asa do nariz para ter visão do interior da fossa nasal, e as válvulas do espéculo são introduzidas no vestíbulo (Figura 1). Esse exame deve ser feito em duas posições.

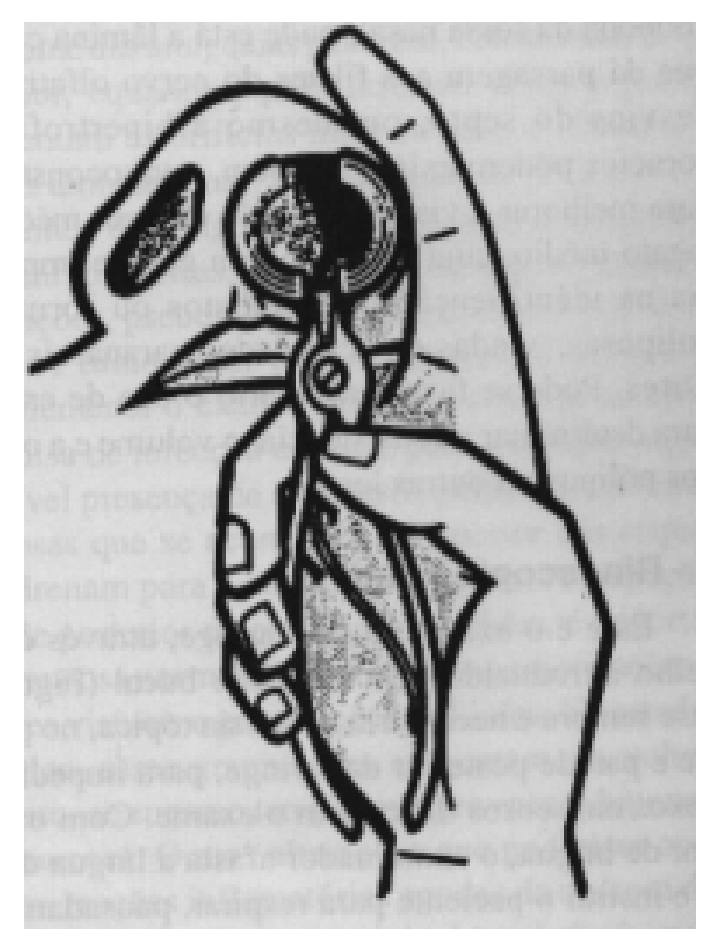

Figura 1 - Rinoscopia anteior. Note-se a posição de colocar e manter o espéculo. 
A primeira posição, onde a cabeça do paciente está em ortostática, permite observar:

- para baixo, o soalho da fossa nasal; para dentro, o septo nasal; para fora, a cabeça do corneto nasal inferior e a entrada, no meato inferior. $\mathrm{O}$ examinador deve estar atento quanto à presença de congestão, hipertrofia ou mesmo degenerações polipóides no corneto inferior, deformidades no septo nasal, e, principalmente, sua relação com o corneto inferior, para se ter uma idéia da permeabilidade nasal. A mucosa que reveste os cornetos pode se apresentar rósea pálida, em processos alérgicos, ou vermelho vivo, em processos infecciosos, agudos. É fundamental o uso de vasoconstrictores nos casos de congestão do corneto inferior. Para tanto uma mecha de algodão, embebida em solução de efedrina $(0,25 \%$ para crianças e $1 \%$ para adultos) é deixada na fossa nasal por 10 minutos. Com isso, a retração do corneto permitirá um exame mais correto e minucioso. No meato inferior, procuramos exsudatos e corpos estranhos que aí se localizam com freqüência.

A segunda posição, onde a cabeça do paciente está em extensão permite observar:

- para fora, a cabeça do corneto médio; para dentro, a porção alta do septo nasal. Entre as duas, há uma pequena fenda, a fenda olfativa que conduz à abóboda da fossa nasal, onde está a lâmina crivosa, que dá passagem aos filetes do nervo olfativo. Os desvios do septo, ou mesmo a hipertrofia dos cornetos podem exigir, também, a vasoconstricção para melhorar a visualização do corneto médio, ou meato médio, cuja inspeção tem grande importância na identificação de exsudatos ou formações poliposas, vindas das cavidades paranasais anteriores. Pode se fazer necessário o uso de estiletes para determinar a consistência, o volume e a origem dos pólipos ou outras lesões.

\section{2 - Rinoscopia Posterior}

Esse é o exame da rinofaringe, através de um espelho introduzido pela cavidade bucal (Figura 2) Quase sempre é necessária anestesia tópica, no palato mole e parede posterior da faringe, para impedir que reflexos nauseosos dificultem o exame. Com o abaixador de língua, o examinador afasta a língua do palato e instrui o paciente para respirar, pausadamente, pelo nariz, provocando assim, um afastamento do palato mole da parede posterior da rinofaringe. Um pequeno espelho, previamente, aquecido é introduzido na orofaringe de um lado e de outro da úvula, refletindo a imagem do cavum e da coana. Observamos então, cuidadosamente, a cauda dos cornetos, a borda posterior do septo nasal, o teto do cavum com o tecido linfóide adenoideano, a tuba auditiva na parede lateral, a presença de pólipo, exsudatos ou degeneração da cauda dos cornetos, massas ou outras lesões.

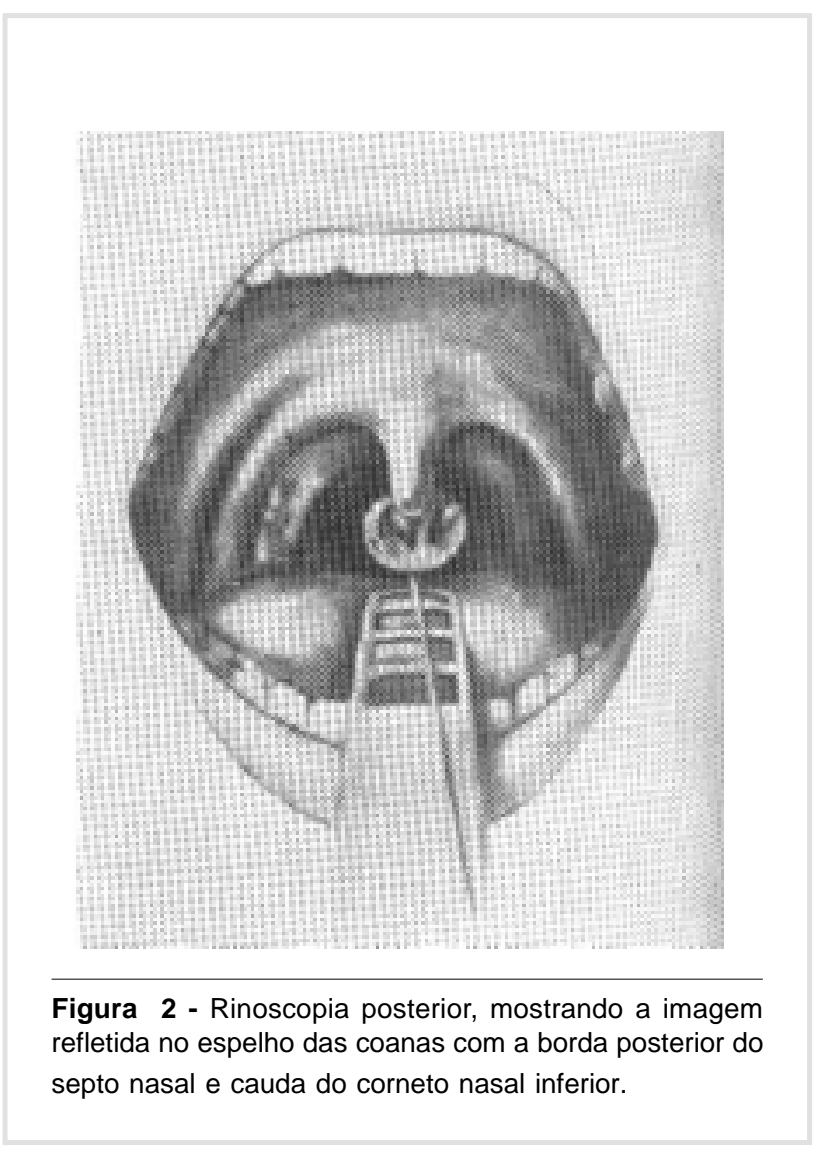

\section{3 - Microrrinoscopia}

O uso do microscópio cirúrgico com lente de $200 \mathrm{~mm}$ de distância focal é muito útil no exame mais minucioso do meato médio. Durante o exame, o corneto médio é luxado em direção ao septo nasal com um instrumento rombo, e o meato médio é exposto permitindo uma melhor visualização de pólipos, exsudatos e degenerações da sua mucosa. A grande vantagem do microscópio, além do aumento proporcionado, é uma qualidade superior de iluminação.

\section{4 - Endoscopia nasal}

O uso de endoscópios, tanto os flexíveis como os rígidos, praticamente, revolucionou o diagnóstico e 
o tratamento das patologias inflamatórias do nariz e cavidades paranasais. Trata-se de um equipamento que oferece excelente definição de imagem e grande profundidade de campo. Através dos endoscópios rígidos, com diferentes graus de inclinação e diferentes calibres, pode-se examinar regiões anteriormente inacessíveis mesmo com o microscópio. A sua indicação se faz necessária, quando o exame rinoscópio simples não é suficiente para firmar uma suspeita diagnóstica.

O exame endoscópico nasal poderá revelar degeneração de cauda dos cornetos nasais, imperfuração coanal, presença de vegetações adenóides na criança e no adulto, individualizar fístula liquórica, pontos hemorragíparos, pólipos nasais ou mesmo carcinoma na coana ou teto do cavum (Figuras 3 e 4 ).

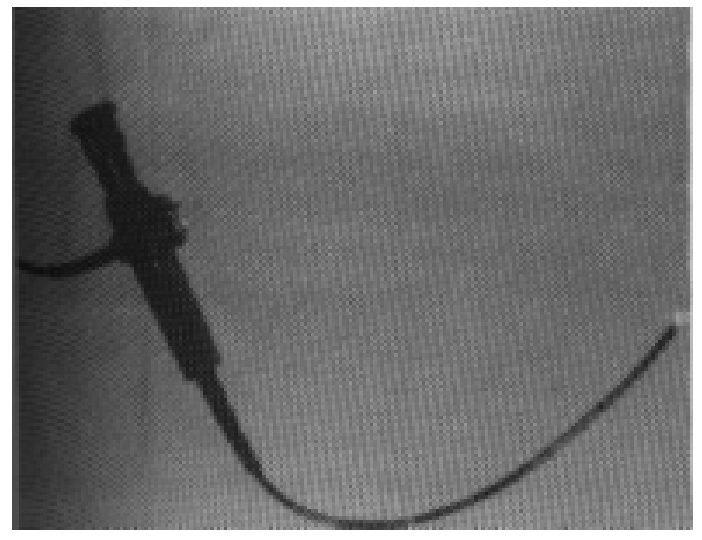

Figura 3 - Nasofaringolaringoscópio Mashida ENT-4L, de $4 \mathrm{~mm}$ de diâmetro.

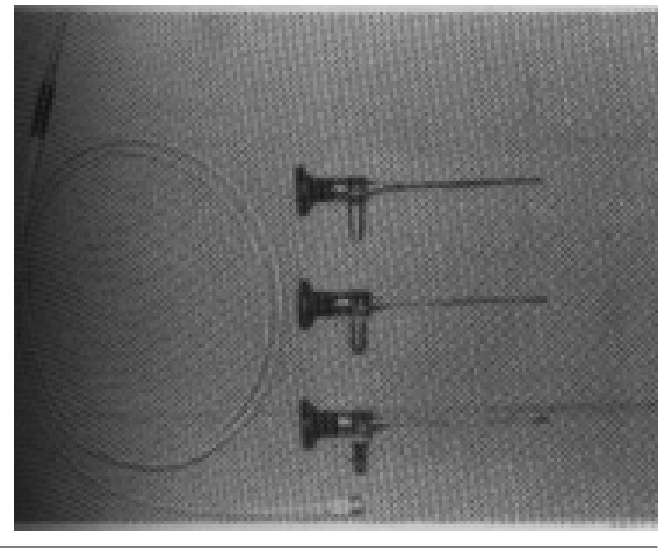

Figura 4 - Conjunto de telescópios tipo Hopkins, Stortz de $2,7 \mathrm{~mm}$ de diâmetro, de $0^{\circ}, 30^{\circ}, 70^{\circ}$.

\section{5 - Sinusoscopia}

O exame endoscópico dos seios paranasais permite avaliar, diretamente, o conteúdo dos seios, o estado da mucosa que os reveste, bem como o estado dos seus respectivos óstios de drenagem. Na maioria das vezes, esse exame requer hospitalização e ambiente cirúrgico.

A rinosinusoscopia é de grande valor no controle pós-operatório ou pós-radioterápico; é um método propedêutico em permanente aperfeiçoamento técnico que, quando acoplado ao sistema de vídeo e TV, facilita, também, o ensino médico.

\section{2 - CAVIDADE BUCAL}

Apesar de muitos pacientes permitirem um exame da cavidade bucal de forma simples e completa, para a maioria deles entretanto, necessitamos do auxílio de um, abaixador de língua. Para um exame mais demorado e completo da orofaringe colocamos uma das extremidades do abaixador no terço anterior ou médio da língua do paciente, a qual será recalcada para baixo, de maneira suave e contínua, recomendando ao paciente para que relaxe os músculos e respire, compassadamente. É importante não se tocar o terço posterior, para que o reflexo nauseoso não seja estimulado. A principal finalidade da orofaringoscopia é o exame das amigdalas palatinas, constituídas do polo superior, equador e polo inferior, cujas superfícies apresentam os orifícios mais ou menos dilatados das criptas amigdalianas. Na inspeção, verificamos o tipo anatômico da amígdala, suas possíveis e diversas reações inflamatórias, a presença ou não de exsudatos, ulcerações, pseudo-membranas, placas mucosas, formações tumorosas, etc. A expressão amigdaliana complementa o exame, principalmente nos casos de pesquisa de infecção crônica, para a comprovação de possível presença de exsudatos purulentos ou massas caseosas que se acumulam no interior das criptas, e que drenam para a cavidade faríngea. A inspeção da parede posterior da orofaringe, também, é importante. Sua mucosa normal contém algumas arborizações vasculares visíveis e granulações linfóides. No estado patológico, essas granulações aumentam em volume e número, ao mesmo tempo, que provocam hipersecreção mucosa. Outras alterações que poderiam ocorrer seriam reações inflamatórias agudas da mucosa de revestimento, ulcerações de etiologia variada, formações flegmonosas, etc. Perturbações da motilidade do véu mole, dos músculos constritores da faringe, bem como 
a sensibilidade da mucosa faríngea, pesquisa dos campos linfonodais cervicais complementam a exploração semiológica da cavidade faríngea. Nos casos de indicação, é importante lembrar o toque digital ou o uso do estilete, a colheita de material para exame bacteriológico e a biópsia.

\section{3 - LARINGE}

Hoje, o laringologista dispõe de importantes meios para um bom exame da laringe: exame externo, laringoscopia indireta e fibroscopia.

\section{1 - Exame externo}

A inspeção da região laríngea já deve ser feita com a anamnese. Enquanto o paciente conta a história de uma moléstia, o examinador está atento no timbre da voz, na existência de ruídos dispnéicos, nos movimentos da saliências e reentrâncias da laringe, formadas às custas das cartilagens tireóideas e cricóideas, na presença de linfonodos hipertrofiados, na região carotídea, na mobilidade da laringe que desce, ligeiramente, na inspiração e sobe na expiração. Em seguida, faz-se a inspeção das regiões vizinhas, observando-se a presença de tiragens nas regiões supra e infraclaviculares ou external, diferenciando as dispnéias das estenoses laringotraqueobrônquicas, das pulmonares ou medicamentosas. O próximo passo é a palpação tanto na laringe como nas regiões vizinhas. Os edemas externos, abalamentos e pontos dolorosos na superfície da laringe auxiliam o diagnóstico de um câncer avançado, de uma pericondrite, de um hematoma ou mesmo de um abscesso laríngeo. Processos inflamatórios e dolorosos, na região aritenóidea podem ser pesquisados comprimindo-se a laringe de encontro à coluna cervical. Imediatamente, o paciente refere dor na região correspondente. No caso de edema nas cartilagens tireóideas, ou infiltração, a sensação de crepitação laríngea desaparece quando é pesquisada ao se mobilizar a laringe, lateralmente, de encontro ao esqueleto vertebral.

\section{2 - Laringoscopia indireta}

É um exame realizado com espelho que fornece uma imagem estática e dinâmica da laringe; é o método mais simples e o primeiro a ser utilizado em qualquer caso suspeito. O paciente deve estar sentado, numa posição bastante ereta, confortável, mas com o corpo e membros verticais. $O$ foco luminoso situado à direita do paciente, e na altura de sua orelha, permite uma luz refletida pelo espelho frontal. O tamanho óti- mo do espelho a ser usado é aquele que permite uma boa mobilidade na orofaringe e que reflete todas as partes da hipofaringe e da laringe do doente. Prendese à ponta da língua, protegida por um fragmento de gaze, com o polegar e o dedo médio da mão esquerda, procurando enrolá-la no próprio dedo médio, através de uma pequena torção da mão. $\mathrm{O}$ dedo indicador apóia-se na arcada dentária superior, e o anular e o mínimo no queixo do paciente. Depois de proteger o freio lingual com gaze, traciona-se, gentilmente, a língua através de um bloco só, formado pela mão esquerda do médico, pelo rosto e língua do paciente. Pede-se ao paciente que não retire a língua, nem faça movimentos de deglutição ou contrações faríngeas. A boa colaboração do paciente e uma pequena nebulização com solução de lidocaina de $10 \%$ na parede posterior da orofaringe e base da língua, permitem um perfeito relaxamento da musculatura faríngea e constituem os elementos básicos para uma boa laringoscopia indireta. $\mathrm{O}$ espelho laríngeo de tamanho próprio, introduzido na faringe do paciente, é seguro com os dedos indicador, polegar e médio da mão direita como se o médico estivesse segurando uma pena de escrever. O espelho é colocado sob a úvula, rechaçando para cima e para trás o palato mole (Figura 5). Cuidase para não tocar nas regiões amigdalianas e parede posterior da faringe, zonas muito reflexógenas. Iniciase, então, o exemplo metódico da imagem laringoscópica e das zonas vizinhas, procurando movimentar ligeiramente o espelho, mas mantendo-o sempre na

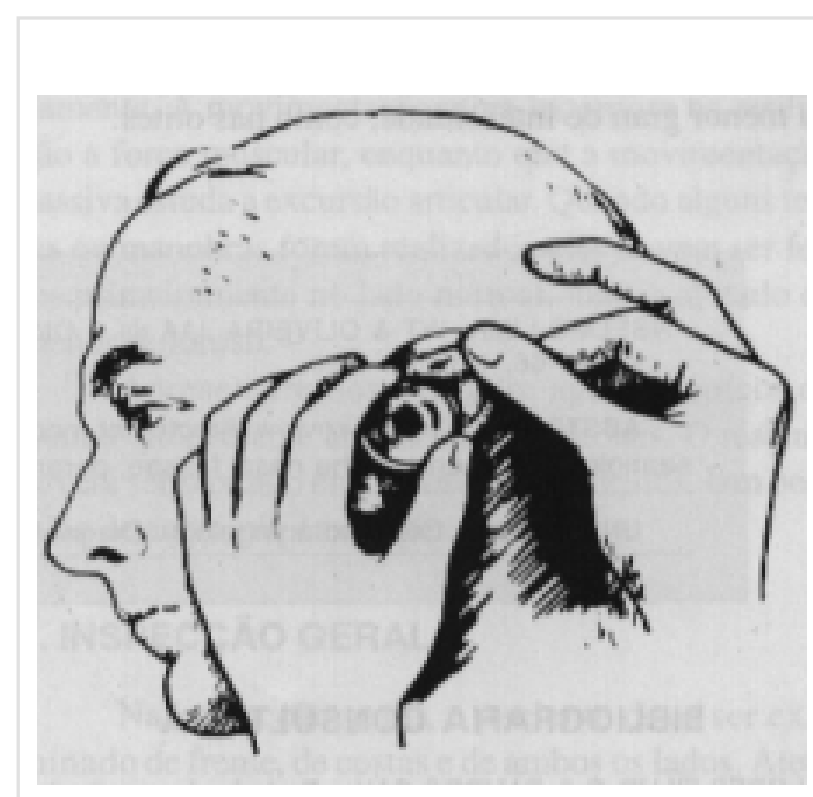

Figura 5 - Laringoscopia indireta 
posição horizontal. É aconselhável, também, seguir uma ordem no exame procurando passo a passo visualizar todo o conjunto faringolaríngeo: bordo livre da epiglode e sua face laríngea; face faríngea da epiglode, valéculas e ligamento glosso epiglótico; zonas aritenóideas D e E, com as eminências de Wrisberg e Santorini; bandas ventriculares D e E; silhueta glótica; cordas vocais D e E; comissura anterior; seios piriformes D e E. Solicita-se ao paciente um maior relaxamento e uma inspiração profunda para melhor visualizar a silhuete glótica e estudar os movimentos das cordas vocais e zonas aritenóideas. Produzindo o fonema "I ", o paciente levanta a laringe e a parede anterior da traquéia. Na maioria dos casos, a laringoscopia indireta é realizada com certa facilidade. Entretanto, em outros se torna difícil. Existe doentes em que a individualidade, a queda e a forma da epiglote e, especialmente, a sensibilidade nervosa não nos permitem fazer uma boa laringoscopia indireta. Nestes casos, o timbre da voz, as disfagias e as dispnéias indicam sempre uma fibroscopia ou laringoscopia direta ou microscopia da laringe, mesmo sob a anestesia geral.

\section{3 - Fibroscopia}

Os nasofaringoscópios flexíveis, atualmente, fazem parte de um exame de rotina para os pacientes com queixas de rouquidão, pois esse é um exame que pode ser feito no consultório com anestesia local. Os fibroscópios para o exame de laringe são de diâmetros e comprimentos menores. A anestesia é local, não só das mucosas da oro e hipofaringe, mas, também, da laringe e da fossa nasal que apresenta maior amplitude; é através dela que será introduzido o fibroscópio. A imagem é um pouco menor, mas permite uma visão estática e dinâmica da laringe. Os fibroscópios rígidos são introduzidos, diretamente, na orofaringe, permitindo um exame menos incômodo para o paciente. A fibroscopia é mais um meio diagnóstico que permite um bom exame da laringe, a realização de biópsia, e que evita qualquer terapêutica prejudicial de prova, quando a laringe não pode ser bem visualizada.

\section{4 - SISTEMA AUDITIVO}

A exploração física do sistema auditivo consiste na inspeção externa, palpação, otoscopia e otomicroscopia.

\section{1 - Inspeção}

Através de uma boa observação, torna-se possível reconhecer os processos inflamatórios e neoplá- sicos do pavilhão auricular, bem como as malformações congênitas, a presença de cistos, fístulas congênitas, coloboma, corpos estranhos, rolhas de cera e pólipos no meato acústico externo, etc.

\section{2 - Palpação}

Esse exame fornece elementos de valor na orientação diagnóstica ao se comprovar pontos dolorosos à pressão do antro mastóideo nas mastoidites agudas, ou da borda posterior da apófise mastóide, nos processos de tromboflebite do seio lateral, assim como do pavilhão auricular nas otites externas agudas. Pode revelar ainda, a presença de reações linfonodais periauriculares nos processos supurativos do ouvido externo e da caixa timpânica.

\section{3 - Otoscopia}

Consiste no exame do meato acústico externo e da membrana timpânica, através do espéculo auricular, empregando-se iluminação direta ou indireta (Figura 6). Ao se introduzir o espéculo deve-se tracionar a orelha para cima e para trás, retificando desse modo as sinuosidades do meato acústico externo. Na criança, especialmente no lactente, essa tração deve ser feita para baixo. Se o meato acústico apresentar rolha ceruminosa, descamação do epitélio ou exsudatos, farse-á, previamente, cuidadosa limpeza, a fim de se proceder ao exame da membrana timpânica, que, nor-

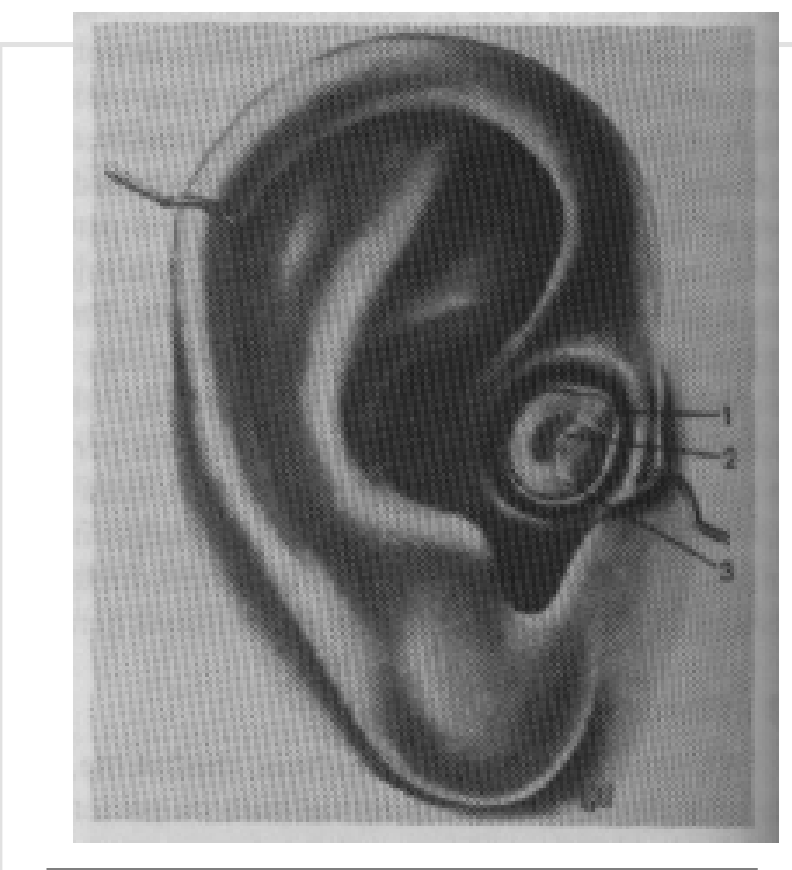

Figura 6 - Figura esquemática para mostrar a técnica do exame otoscópico (lado esquerdo). 
malmente é de cor pérola, colocada, no fundo do meato acústico externo, ligeiramente, inclinada para dentro (principalmente no lactente), fazendo ângulo de cerca de $45^{\circ}$ com a parede inferior do meato acústico. Através da membrana timpânica, em seu centro e em direção oblíqua, de cima para baixo e de diante para trás, percebe-se, nitidamente, a saliência do cabo do martelo, que termina na extremidade superior por diminuto relevo acuminado: a curta apófise do martelo, de onde se originam 2 pequenas pregas ou saliências, uma anterior e outra posterior: são as pregas timpanomaleares, acima das quais se encontra a parte flácida da membrana de Shrapnell. Da extremidade inferior do cabo do martelo ou umbigo da membrana, dirigindo-se para diante e para baixo, verifica-se a presença do ponto luminoso de Politzer, devido à reflexão dos raios luminosos vindos do espelho frontal (Figura 7). Para facilitar a descrição da localização das lesões da membrana timpânica, esta é dividida de acordo com um mostrador de relógio, ou em 4 quadrantes (ântero-superior, ântero-inferior, póstero-superior e póstero-inferior) por meio de 2 linhas que se cruzam em ângulos retos, uma delas passando pelo eixo do cabo do martelo. No estado normal, a membrana timpânica é mobilizável, o que se pode comprovar por intermédio do espéculo pneumático de Siegle. No estado patológico, todos esses elementos anatômicos da membrana timpânica podem estar alterados em maior ou menor grau de intensidade, como nas otites.

\subsection{Otomicroscopia}

É o mesmo exame explicado anteriormente, só que nesse caso a iluminação é dada pelo microscópio cirúrgico com lente de $200 \mathrm{~mm}$ de distância focal, permitindo assim análise muito mais minuciosa e completa da membrana timpânica. A melhor visualização fornece uma limpeza mais completa do conduto e facilita quando da necessidade de parecentese, retirada de corpos estranhos ou rolhas ceruminosas, etc.

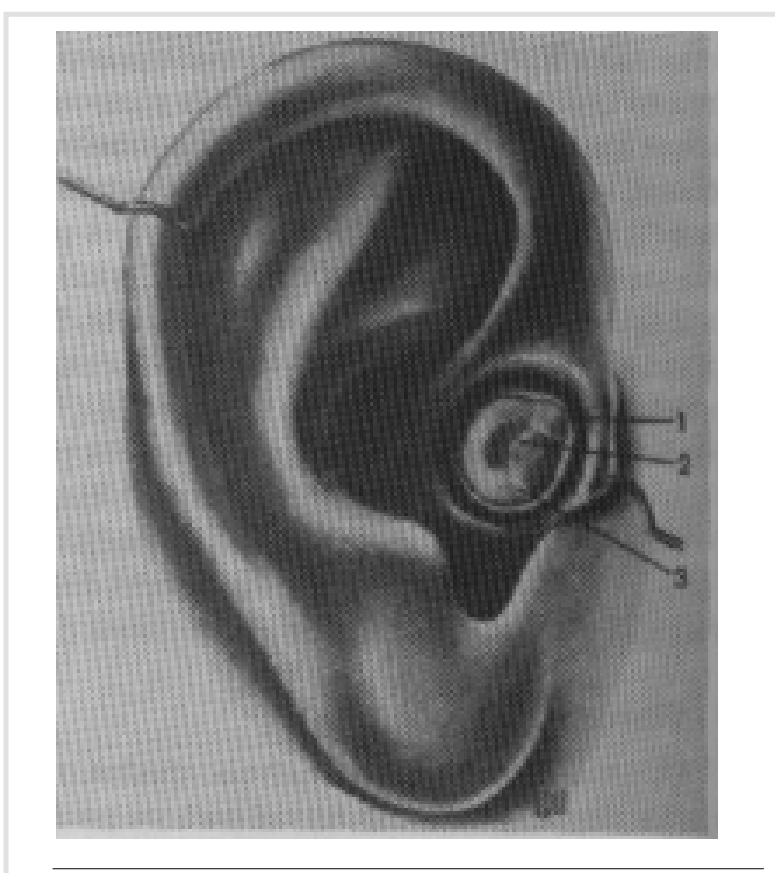

Figura 7 - Ouvido direito. 1 - Membrana de Shrapnell; 2 - Cabo do martelo; 3 - Triângulo luminoso.

ANSELMO-LIMA WT \& OLIVEIRA JAA de Otorhinolaryngologic Semiology. Medicina Ribeirão Preto, 29: 61-66, jan./mar. 1996.

ABSTRACT: In this review directed at medical students and non specialist physicians, the major semiologic elements of the nasal fossae, paranasal sinuses, larynx, pharynx and ear are presented.

UNITERMS: Otorhinolaryngology. Diagnosis, Otorhinolaryngologic.

\section{BIBLIOGRAFIA CONSULTADA}

1 - LOPES FILHO O \& CAMPOS CAH. Tratado de otorrinolaringologia. Roca Editora, São Paulo, 1994.

2 - HUNGRIA H. Otorrinolaringologia. Guanabara Koogan Rio de Janeiro, 1991.
3 - COSTA SS; CRUZ OLM \& OLIVEIRA JAA. Otorrinolaringologia - Principio e prática. Artes Médicas, Porto Alegre, 1994.

Recebido para publicação em 04/03/96

Aprovado para publicação em 14/03/96 